\title{
Decapitation by the Force to the Body: A Case Report and a Review of the Literature
}

\section{Ryuichi Katada ${ }^{1,3 *}$, Yoko Nishitani ${ }^{2}$, Shunichiro Okazaki ${ }^{1}$ and Hiroshi Matsumoto ${ }^{1,3}$}

${ }^{1}$ Department of Legal Medicine and Molecular Alcohology, Sapporo Medical University School of Medicine, S-1 W-17, Chuo-ku, Sapporo 060-8556, Japan ${ }^{2}$ Department of Forensic Medicine, Graduate School of Medical Sciences, Kumatomo University, 2-39-1 Kurokami, Kumamoto 860-8556, Japan

${ }^{3}$ Department of Legal Medicine, Osaka University Faculty of Medicine, 2-2 Yamadaoka, Suita 565-0871, Japan

\begin{abstract}
Most of decapitation has been performed by sharp and hanging rope. A 41-year-old man was found died with decapitation on the roof of second story in the apartment where he lived. The separated head was placed apart from his torso. Each edge of the parts was relatively sharp. There were also a number of incised wounds in the face, neck, left arm, and abdomen. All wounds were accompanied with subcutaneous hemorrhage and hematoma, suggesting that these wounds had been performed during survival. The separated head was accompanied with the larynx, pharynx and the parts of lungs and heart. Severe recessus ran from his right shoulder to left lateral chest, which indicates that the victim's chest was severely hit by the unsharp object such as the railing. Then the force of inertia was acted toward the head from the toe. The head attachments were pulled out by the gigantic force of inertia. The victim was injured several incised wounds on the neck and then received strong force to chest, which caused decapitation inducing death. The present case is the first report among decapitation. Force to the body causes decapitation as if wounds are injured by the sharp instrument.
\end{abstract}

Keywords: Decapitation; Falling; The force to the body

\section{Introduction}

Decapitation is rarely experienced for forensic pathologists except for the putrefaction corpus decomposed by invaders. However, it has been very important for forensic pathologists to think of the cause of death, antemortem or post-mortem decapitation, and the instrument for decapitation. Postmortem decapitation is often caused after hanging. Rarely, victim is murdered and the corpse is unlawfully disposed after death for the purpose of hiding or carrying easily. Antemortem decapitation is divided into suicide, homicide and accident by classification of the cause of death. Antemortem decapitation is generally performed by a lot of instruments, such as knife, saw, guillotine, rope, chain, and so on (Table 1). In most of the cases, these objects act around the neck directly. The force for decapitation by blunt instrument is strongish, such as vehicle-assisted ligature strangulation [1-8], suicidal hanging [9-12], rarely, attacks by animal such as dog and so on $[13,14]$, and explosion [15]. However, any strong force is not necessary for decapitation by sharp instrument [16,17]. Most of suicidal decapitations can be performed by hanging rope [1,2,6,8-12], wheels of train [4], and sharp instrument [16]. Homicidal decapitation can be mostly performed by sharp instruments such as knife, saw and scissors [17]. Türk et al. reported four cases of homicidal decapitation, which decapitation was inflicted at postmortem after killing the victim in three cases and decapitation was inflicted during survival in one case [17]. Ihama et al. reported an accidental decapitation by the movement of the chain [5]. Buschmann et al. reported that the dogs attacked the neck of 3-week-old male infant and swallowed his head [13]. Therefore, decapitation can be caused by the force to the narrow width in the neck directly and strongly. Indirect force to the neck may be difficult to cause decapitation. In this report, we experienced rare case of decapitation due to the force to the body. Decapitation is caused by indirect force to the neck.

\section{A Case}

A 41-year-old man was found dead from decapitation (Figure 1). The separated head and body were apart from each other. The place was the roof of second story in the apartment with fourteen stories where he lived. The railings of the roof were bloodstained severely. The floor and the wall were also bloodstained (Figure 1a). In the head side, the bloodstain ran toward to the body (Figure $1 \mathrm{~b}$ and 1c). Police speculated that the man had fallen from $14^{\text {th }}$ story $(40 \mathrm{~m})$, after then, the body had been attacked to the railing. His shoes were left in the exit at the $14^{\text {th }}$ story. The railings of $14^{\text {th }}$ story were blood stained. The blood stained knife was found in his room and huge bloodstains were also left anywhere in his room.

Autopsy was performed for diagnosis of cause of death. The height and weight were $167.5 \mathrm{~cm}$ and $54.2 \mathrm{~kg}$, respectively. Postmortem lividity was space throughout the body. Any petechiae in the mucosa was not apparent. The blood in the head and body was almost lost and remained blood did not show coagulation. The wounds of the edge of the neck were relatively sharp around the neck and several incised wounds existed in parallel to the edge. Abrasions or bruises did not exist in the neck lesion. On the other hand, there were some cut wounds in his right forearm and left upper abdomen. The head was accompanied with the larynx, pharynx and the part of lungs and heart. In the chest, the recessus ran from right shoulder to left lateral chest at an equal width (Figure 2). The tissues including muscle, bone, connective tissue and internal organs under the recessus were separated in the chest. Hemorrhage was observed slightly surrounding these tissues. There were middle cranial base fractures, mandibular bone fracture, multiple costal bone fractures in the dorsal side, and left ankle fracture. Vertebral

*Corresponding author: Ryuichi Katada, Department of Legal Medicine, Osaka University Faculty of Medicine 2-2 Yamadaoka, Suita 565-0871, Japan, Tel: +81 6-6879-3112; Fax: +81 6-6879-3119; E-mail: katada@legal.med.osaka-u.ac.jp

Received March 09, 2014; Accepted June 09, 2014; Published June 15, 2014

Citation: Katada R, Nishitani Y, Okazaki S, Matsumoto H (2014) Decapitation by the Force to the Body: A Case Report and a Review of the Literature. J Forensic Res 5: 232 doi:10.4172/2157-7145.1000232

Copyright: ( 2014 Katada R, et al. This is an open-access article distributed under the terms of the Creative Commons Attribution License, which permits unrestricted use, distribution, and reproduction in any medium, provided the original author and source are credited. 
Citation: Katada R, Nishitani Y, Okazaki S, Matsumoto H (2014) Decapitation by the Force to the Body: A Case Report and a Review of the Literature. J Forensic Res 5: 232 doi:10.4172/2157-7145.1000232

Page 2 of 3

\begin{tabular}{|c|c|c|c|c|}
\hline Type of decapitation & Pathological findings of the neck & Other wounds & Mode of Death & References \\
\hline Sharp tool & $\begin{array}{l}\text { Clear-cut wound }[16,17] \\
\text { Band-like abrations, } \\
\text { and several incisions [16] }\end{array}$ & $\begin{array}{l}\text { Blunt facial injuries, several stab } \\
\text { wounds in the body }[16] \\
\text { None }[16,17]\end{array}$ & Suicide/Homicide & {$[16,17]$} \\
\hline Hanging & $\begin{array}{l}\text { Irregularly shaped defects [9] } \\
\text { Sharp-edged lacerations with } \\
\text { band-like abrasions [10] } \\
\text { Laceration with wavy abrasion [11] } \\
\text { Circumferential skin abrasion [12] }\end{array}$ & None [9-12] & Suicide & {$[9-12]$} \\
\hline Animal & $\begin{array}{l}\text { Bite marks and tissue defects [13] } \\
\text { Tooth puncture wounds [14] }\end{array}$ & None $[13,14]$ & Accident & {$[13,14]$} \\
\hline Explosion & Sharp-edged gaping lacerations [15] & $\begin{array}{l}\text { Lacerations and contusions } \\
\text { in all region [15] }\end{array}$ & Suicide/Homicide & [15] \\
\hline Vehicle assisted & $\begin{array}{l}\text { Clear-cut wounds with demarcated } \\
\text { abrasions }[1,4,6,8], \\
\text { Band-like abrations }[2,5] \\
\text { Irregular }[3,4] \\
\text { Liner abrasions with thinner erosion [7] }\end{array}$ & $\begin{array}{l}\text { None }[1,2,4,6-8] \\
\text { Abrasions on the limbs [3] } \\
\text { Rib fractures [5] }\end{array}$ & Suicide/Accident & {$[1-8]$} \\
\hline Force to the body & $\begin{array}{l}\text { Sharp-edged lacerations with } \\
\text { several incision parallel to the edge. } \\
\text { The head was accompanied with the } \\
\text { larynx, pharynx and the part of lungs } \\
\text { and heart }\end{array}$ & $\begin{array}{l}\text { Recessus ran from right shoulder } \\
\text { to left lateral chest. Internal tissues } \\
\text { and organs under the recessus were } \\
\text { separated }\end{array}$ & Unknown & Present case \\
\hline
\end{tabular}

Table 1: The review of the literature on decapitation.

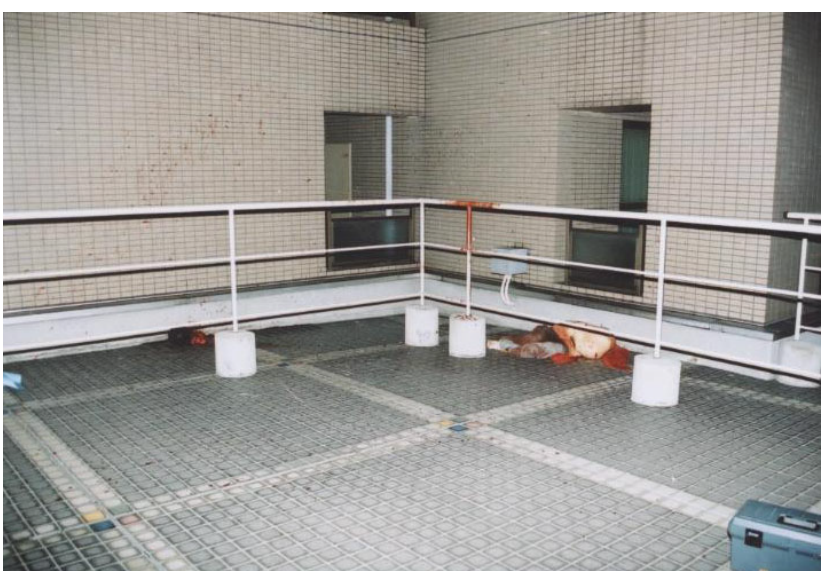

Figure 1a: The general view of the place where the victim was found.

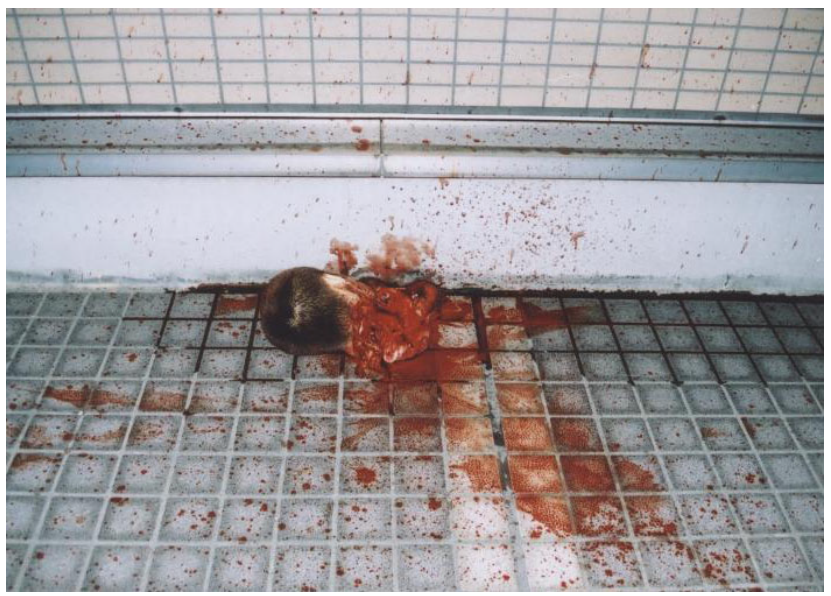

Figure 1b: Head side view.

bones were crush-fractured and separated between Th9 and Th10. And aorta was separated in the same height of vertebral bone fracture. Heart

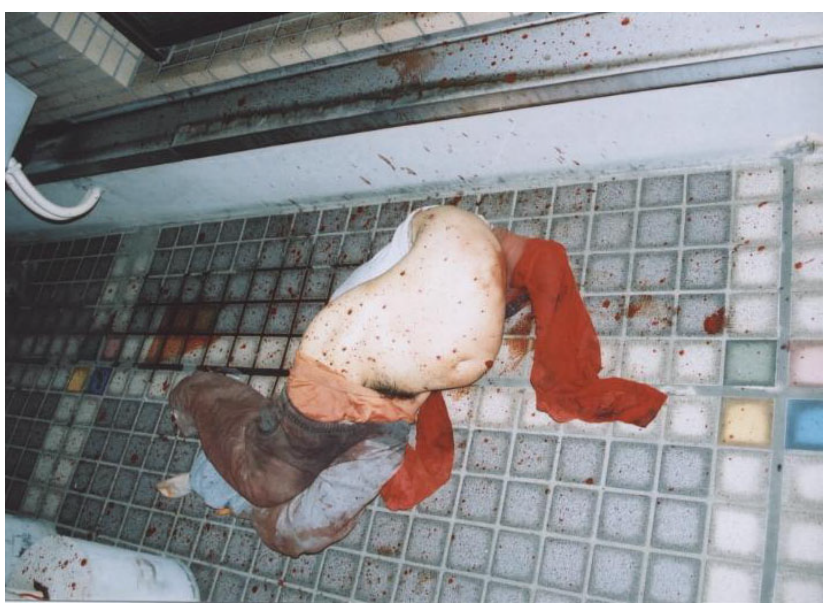

Figure 1c: Body side view.

and lungs were divided into two parts, respectively. Autopsy findings indicated that the victim died from decapitation.

\section{Discussion}

In the present case, the autopsy finding showed that the head was separated from the body, but neither ligature mark nor tissue decompression except for the several cut wounds existed in the neck. Subcutaneous tissue hemorrhages were only found under the cut wounds. In the chest, there was remarkably recessus which ran from right shoulder to left lateral abdomen. The heart was separated to two parts, and the one of the heart accompanied the head and the other remained body. The lungs and trachea were also divided into two parts, as same way of the heart, the one of the lung and trachea accompanied the head and the other remained the body. The spine was separated at T9/T10, however, cervical spine fractures and separation were not found. These findings indicate that the hard, sharpless, round and thin object attacked the body of the victim from his right shoulder to left abdomen. It is considered that the cut wounds had already existed in the neck for the reason of the vital reaction such as the subcutaneous hemorrhage and hematoma. Neck had vulnerability for holding 


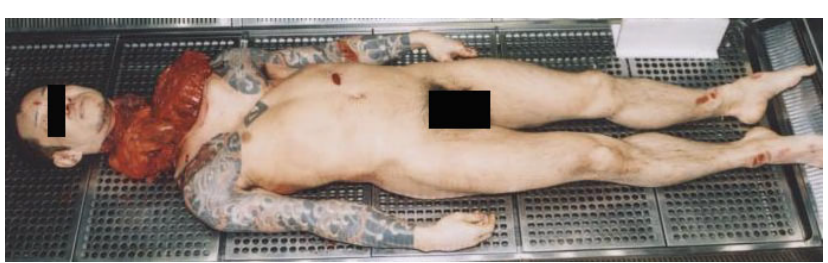

Figure 2: The whole view of victim. The head was accompanied with the larynx, pharynx and the part of lungs and heart. In the chest, the recessus ran from right shoulder to left lateral chest.

the head as the incised wounds had already existed. As the result of vulnerability of neck, decapitation was caused by the indirect force to the neck. Circulation was remained shortly after decapitation because the hemorrhages around the muscle, spinal bone and internal organ under the recessus were found, which indicates that the victim had lived just after decapitation. Furthermore, the remained blood in the body did not show coagulation, which is indicative of acute death. So, the victim died from decapitation accompanied huge hemorrhage and neuronal shock. It is difficult to diagnose this case as suicidal, homicidal or accidental because the place of the cut wounds were able to be injured by himself and the depth of wound was not so much. We presumed that his position was prone at the time of hitting to the railing, and after hitting the chest, the head with the attachments was pulled out by the force of inertia. It is unknown whether he cut his neck by himself for suicide or the other people cut his neck for homicide. The head was separated and accompanied the tissues which included the larynx, pharynx, the part of lungs and the part of heart. The bloodstains existed not only on the floor but also on the separated body. Therefore, it is speculated that the man fell to the railing and hit his chest. After then, the head was separated from the body and jumped upward while bleeding.

Table 1 shows a literature about decapitation including the present case. In regardless of the present case, decapitation had been occurred by the direct force to the neck. Generally, forensic pathologists can consider any objects for decapitation. It seems that decapitation by the force to the body cannot occur in the intact neck. The huge force such as the falling from high altitude and car accident can be necessary for decapitation in the indirect force to the neck.

In the present case, no cervical spine fracture was observed, but thoracic spine was crushed and separated. Zhu et al. reported the case with self-decapitation by suicidal hanging from a river bridge [11]. In that case, there were fractures in the axis at the parts interarticulares, which indicates a traction force combined with anteroflexion of the head by falling from a height. Cervical spine fractures in the decapitation are indicative of head movement at the time of decapitation. In the present case, however, cervical spine fractures were not recognized, and we considered that severe head movement did not occur. In car accident, the seat belt on the chest and abdomen of the driver or assistant can operate huge force to the chest. If the accident is head-on collision or nearly accident, the front-grasses crash and run to the driver and assistant, which can cause incised wounds. And if the force is very gigantic, head can be separated from the neck resembling to the present case. We recommend that drivers and assistants, especially children, should put on the seat belt following manufacture's manual.

In conclusion, we showed a decapitation case in which the considerable force acted to the chest and caused decapitation in vulnerable neck. The decapitation can be caused by the indirect force to the neck if there are some wounds in the neck. So, we should check carefully the edge of the neck and consider the mechanism of decapitation if there are some wounds in other region.

\section{References}

1. Samberkar PN (2012) Motor vehicle-assisted ligature strangulation causing complete decapitation: an autopsy report. Am J Forensic Med Pathol 33: 86-87.

2. Hejna P, Havel R (2012) Vehicle-assisted decapitation: a case report. Am J Forensic Med Pathol 33: 73-75

3. Zoja R, Gentile G, Giovanetti GF, Palazzo E (2011) Death by complete decapitation of motorcyclist wearing full face helmet: case report. Forensic Sci Int 207: e48-50.

4. Zoja R, Battistini A, Gentile G (2009) Death with complete decapitation: report of four suicides by train. Am J Forensic Med Pathol 30: 303-306.

5. Ihama Y, Miyazaki T, Fuke C, Niki H, Maehira T (2008) Complete decapitation of a motorcycle driver due to a roadblock chain. Int J Legal Med 122: 511-515.

6. Zhao D, Ishikawa T, Quan L, Li DR, Michiue T, et al. (2008) Suicidal vehicleassisted ligature strangulation resulting in complete decapitation: an autopsy report and a review of the literature. Leg Med (Tokyo) 10: 310-315.

7. Racette S, Vo TT, Sauvageau A (2007) Suicidal decapitation using a tractor loader: a case report and review of the literature. J Forensic Sci 52: 192-194.

8. Türk EE, Tsokos M (2005) Vehicle-assisted suicide resulting in complete decapitation. Am J Forensic Med Pathol 26: 292-293.

9. Hayashi T, Buschmann C, Tsokos M (2012) Complete post-mortem decapitation in suicidal hanging. Forensic Sci Med Pathol 8: 463-465.

10. Dedouit F, Tournel G, Bécart A, Hédouin V, Gosset D (2007) Suicidal hanging resulting in complete decapitation--forensic, radiological, and anthropological studies: a case report. J Forensic Sci 52: 1190-1193.

11. Zhu B, Quan L, Ishida K, Oritani S, Taniguchi M, et al. (2000) Decapitation in suicidal hanging--a case report with a review of the literature. Leg Med (Tokyo) 2: 159-162.

12. Tracqui A, Fonmartin K, Géraut A, Pennera D, Doray S, et al. (1999) Suicidal hanging resulting in complete decapitation: a case report. Int J Legal Med 112: 55-57.

13. Buschmann C, Solarino B, Püschel K, Czubaiko F, Heinze S, et al. (2011) Postmortem decapitation by domestic dogs: three case reports and review of the literature. Forensic Sci Med Pathol 7: 344-349.

14. Tsokos M, Byard RW, Püschel K (2007) Extensive and mutilating craniofacial trauma involving defleshing and decapitation: unusual features of fatal dog attacks in the young. Am J Forensic Med Pathol 28: 131-136.

15. Tsokos M, Türk EE, Madea B, Koops E, Longauer F, et al. (2003) Pathologic features of suicidal deaths caused by explosives. Am J Forensic Med Pathol 24: $55-63$.

16. Shorrock K (2002) Suicidal decapitation by guillotine: case report. Am J Forensic Med Pathol 23: 54-56.

17. Türk EE, Püschel K, Tsokos M (2004) Features characteristic of homicide in cases of complete decapitation. Am J Forensic Med Pathol 25: 83-86. 